\title{
Correspondence
}

\author{
Editor: Greg Wilkinson
}

Contents: Rudolph Hess's mental illness/Expressed emotion and first episodes of schizophrenia/A comparative trial of amitriptyline and fluoxetine/ Tuberous sclerosis and psychosis/Comparative trial of a new antidepressant/Depressed mood after stroke/Long-term psychiatric patients in the community/Pseudo-AIDS, AIDS panic or AIDS phobia?/Neuroleptic malignant syndrome (NMS): a misnomer?/Edinburgh Post-natal Depression Scale/ Predictions of outcome in depressive illness/The Hungerford Massacre and its aftermath/Behaviour disorder in childhood re-assessed/Indecent exposure - a report of a female/Mania following head injury/Acute psychotic episode caused by the abuse of phensedyl/Compensation psychosis/Consent to investigation.

\section{Rudolph Hess's Mental Illness}

SIR: The recent suicide of Rudolph Hess, aged 91, in Spandau Prison recalls the spirited controversy about his correct psychiatric diagnosis (Dicks et al, 1947; Slater, 1972). When Hess parachuted into Scotland on 10 May, 1941, he was Deputy Führer and a close friend of Hitler. Hess claimed he made the jump in order to make contact with the Duke of Hamilton, who would take him to King George; together they would arrange to stop the war. The immediate impetus for Hess's flight to Scotland, according to his own account, was a dream by a friend whom he believed was a prophet. German radio attributed Hess's flight to "an illness of many years' standing. . .mental derangement" and added that "the National Socialist Party regrets that this idealist fell a victim to his hallucinations."

Almost immediately Hess was noted by his captors to be depressed and to be expressing beliefs about a plot to poison him. Within one month of his landing he was examined by psychiatrists - BrigadierGeneral J. R. Rees and H. V. Dicks. The latter spoke fluent German. Rees diagnosed Hess as suffering from "a psychopathic personality of the schizophrenic type", while Dicks' immediate impression was "typical schizophrenic"; Dicks later diagnosed "paranoid psychosis". In subsequent months Hess was noted to have auditory hallucinations, much evidence of delusional thinking, and odd behaviour "such as lying with his fingers in his ears smiling to himself". He also made two suicide attempts, fracturing a femur in a leap shortly after his arrival in 1941 and stabbing himself in the chest in 1945. Hess's clinical picture was complicated, however, by intermittent amnesia "which varied with circumstances and with the observer, and at times suggested malingering rather than hysteria".

On 10 October, 1945, Hess was taken to Nuremberg to stand trial for war crimes; the question was whether he was mentally competent to stand trial. A Rorschach protocol indicated "the possibility of a psychotic episode". However, initial psychiatric examination by Major Kelley concluded that Hess had "a severe psychoneurosis of the hysterical type". Hess was therefore examined by American, British, Russian, and French physicians. The Americans (D. Ewan Cameron, Nolan D. C. Lewis, and Paul L. Schroeder) concluded that Hess "is suffering from hysteria characterised in part by loss of memory" and "is not insane at the present time in the strict sense of the word". The British (Lord Moran, J. P. Rees, and George Riddoch) diagnosed Hess as "a psychopathic personality" with "a marked hysterical tendency" and declared that "He is not insane in the strict sense". The Russians (Professors Krasnushkin, Sepp, and Kurshakov) labeled Hess's illness "a psychogenic paranoid reaction" with "hysterical amnesia", and said "there are no changes typical of the progressive schizophrenic diseases". The French (Professor Jean Delay) participated in both the American and Russian examinations and tried to conduct a narcoanalysis of Hess, but he refused. Hess was allowed to stand trial, was found quilty and was sentenced to life imprisonment.

Slater (1972) published a little-known but sharplyworded critique of the psychiatric conclusions, and especially of the part played by J. P. Rees. Slater claimed that, "the conclusion is irresistible that Rudolph Hess had a schizophrenic psychosis... The psychotic process came in a series of acute attacks. . It is very difficult to explain the incapacity or 
unwillingness on the part of the psychiatrist [sic] to reach this diagnosis." Slater continued, "If the diagnosis of schizophrenia is correct, then there would seem to have been serious deficiencies in the clinical judgment or the open-mindedness of a number of distinguished world psychiatrists ... The diagnostic blindness, the failure to reach an obvious conclusion becomes a problem in its own right, demanding explanation."

Rees, according to Slater, was the key to the error. Rees's understanding of "psychopathological phenomena on exclusively psychodynamic lines" and his contention "that diagnosis is a bagatelle" led to "the results of grave misconceptions of the task of the psychiatrists of what constitutes psychiatric knowledge, and of the function of psychiatry as a medical discipline vis-à-vis the individual patient". Rees, as the only psychiatrist on the British examining team and as the only person present with extensive involvement with the case, was in a position to influence the others. This, in Slater's opinion, "led to a trial which seems now to have been a miscarriage of justice".

In his 1972 article Slater called for the release of the subsequent psychiatric records on Hess when he died, to settle the diagnostic issues. From 1946 until his recent death, over 41 years of such records have accumulated. What effect, for example, did Hess's psychiatric status have on the decision not to release him from Spandau? If Hess was psychotic, was he treated during those 41 years? What effect did press reports that Hess might be malingering have on the decision to try him at Nuremberg? Since Hess was a Deputy Führer whose flight to the West was deeply embarrassing to Hitler, did political considerations enter into the diagnostic decision to not label him as insane? If Hess was psychotic, what was his mental status as Deputy Führer when he and Hitler were formulating the policies which led to the war? It is also interesting to contrast the case of Hess, apparently psychotic but found fit to stand trial, with the simultaneous case in the United States of Ezra Pound, who was not psychotic but claimed to be unfit to stand trial on 19 counts of treason (Torrey, 1983).

In the interest of history, the psychiatric records of Rudolph Hess should be made available for professional examination.

Twin Studies Unit/NIMH

E. FULLER TORREY

St Elizabeth's Hospital

Washington, DC 20032

\section{References}

Dicks, H. V., Graham, J. G., Johnston, M. K., Jones, D. E., Kelley, D. M., Phllups, N. R., Grbert, J. G. \& Reps, J. R. (1947) The Case of Rudolph Hess: A Problem in Diagnosis and Forensic Psychiatry. London: David Higham Associates Ltd.
SLATEr, E. (1972) The illness of Rudolph Hess: a phenomenological analysis. In Dimensions de la Psiquiatria Contemporanea (ed. C. P. de Francisco). Mexico City: Editorial Fournier.

TORREY, E. F. (1983). The Roots of Treason: Ezra Pound and the Secret of St Elizabeths. New York: McGraw Hill.

\section{Expressed Emotion and First Episodes of Schizophrenia}

SIR: The debate about the validity of the Northwick Park Study in the papers by Mintz et al and Macmillan et al (Journal, September 1987, 151, 314-323) highlights a number of important issues about the EE concept. The level of discrimination between high and low EE in predicting relapse among first-episode schizophrenics, whether significant or not, is certainly lower than in previous studies of EE in undifferentiated samples. In fact, Leff \& Brown (Journal, April 1977, 130, 417) have previously revealed that the nine-month relapse rates for high $\mathrm{EE}$ first admissions is $38 \%$ (compared with $13 \%$ for low EE) and $69 \%$ (compared with $17 \%$ ) for readmissions. If high/low EE are stable characteristics, why should such temporal changes in predictive power be observed? The possibility that EE may in fact be an unstable characteristic is revealed in the recent largescale study of Hogarty et al (1986): $25 \%$ of the high EE sample not exposed to family treatment 'spontaneously' reduced to low EE, compared with $39 \%$ who reduced under family treatment. In both groups no relapse was observed, suggesting perhaps that the spontaneous reduction in high EE was genuine and not an artefact of measurement. It seems that there is an important developmental dimension in the genesis of stable EE which is concerned with the cumulative interaction of inherent schizophrenic vulnerabilities and the family system (Birchwood \& Smith, 1987).

Macmillan et al discuss the applicability of EE: only one-third of their sample come from a family home, and of these only a minority were high EE. Our experience is roughly similar, although we have observed that many first admissions return to the family home subsequently; McCreadie \& Robinson (Journal, May 1987, 150, 640-644) found that 50\% of their undifferentiated sample lived with a relative. It is not at all clear to us that low EE families cope in a 'model' way; in some cases we have observed that families manage the burden of living with schizophrenia in such a way as to exacerbate other clinical or social features, such as social withdrawal (Birchwood \& Smith, 1987). The prelevance of high EE does not therefore adequately reflect the therapeutic or service implications of family interventions.

Finally, Macmillan et al draw attention to the comments of Hogarty et al (1986) that family interventions delay rather than prevent relapse and that 